\title{
LEARNING MANAGMENT THEORY: HOW EXPERTS FOSTER LEARNING IN HIGHER EDUCATION AND PROFFESSIONAL PRACTICE ENVIRONMENTS
}

In this article I introduce learning management theory (LMT) as a framework for the study and design of learning in higher education and professional practice environments. LMT's focus is on what experts do to foster learning, its unit of analysis is an "expertise-driven skill unit" composed of one or more individuals of various degrees of expertise, their artifacts, and the practices by which the former engage the later. Examples of expertise-driven skill units are a teacher engaged with his/her students in the physical or virtual classroom, a team of software design engineers, or a scientist and her assistants at the research lab. Learning management (LM) is the process in which expertise-skill units engage with the purpose of delivering learning for themselves, others and their disciplines. The construct can be described in terms of a set of complementary concepts: 1. LM temporal dimensions, 2. LM best practices, 3. LM design principles, and 4. LM tools. LM concepts are derived from a "complexity assumption” to domain learning and expert cognition: each concept reflects a different perspective on the complex phenomenon of LM. Because of its focus on experts and the expertise-driven skill units in which they participate, LM dissolves the dichotomy between learning in the physical or virtual classroom and learning in professional practice, gives experts and novices a formative common platform for learning and development in higher education and the workplace.

Keywords: Faculty development, learning environments, professional learning, cognitive engineering, applied cognitive science, human computer interaction.

\section{INTRODUCTION}

In this article I present a theoretical and methodological framework, learning management theory (LMT), for the study of the aspects of expert performance that foster learning - the expert's own learning, the learning of novices, and the learning that results on the development of their domains of expertise. LMT focuses on the following research questions: In complex domains of knowledge such as aircraft navigation, professional teaching and software programming, what do experts do to foster learning in novices, themselves, their colleagues and their disciplines? Given the growing presence of technology in educational and work environments, how can we describe what experts do to foster learning in ways that acknowledge the complex human-machine systems that constitute the learning environments of the present? The article proposes a construct, learning management (LM), as a theoreticalpractical response to these questions.

Learning Management is a construct that rejects either/or dichotomies in learning and cognition: technology versus brain, 
individual versus environment, behavioral versus constructivist, etc. Instead, it defines its concepts in ways that allow for the consideration of various epistemological perspectives. In what follows I introduce these core concepts, and then I illustrate them by describing a particular case, professional teaching in higher education, in terms of the construct.

\subsection{Either/or perspectives in the study of learning in complex domains}

Humans' brains are only part of the picture of intelligent performance in complex content domains. In aircraft navigation, classroom teaching and software programming, learning to perform as an expert requires mastering the practices and artifacts of the domain - learning in complex content domains is a situated process that requires expert's support (Lave et al. 1981). Famously, Herbert Simon recognized that 'learning is difficult to understand if we focus only on the science of the artificial individual» [10, p. 32); yet, even when he recognized that the complexity of human intelligent performance depends not only on the properties of the individual organism but to the properties of the environment in which it happens, his breakthrough studies of expertise and expert performance focused on learning as the internalization of knowledge by the brain [24]. Traditionally, learning has been seeing as something that happens to the brain and therefore studies of expertise traditionally focus on how experts and novices differ in the way that their knowledge is organized in their brain, how they have memorized it and organize it in clusters of readily available information for use [4, p.17]. From this approach a body of knowledge has emerged about expert performance in complex domains that indicates that expert performance is domain specific, context dependent and indexical, i.e. it requires the right context and a great body of domain specific knowledge and experiences organized in ways that allow for their retrieval when needed [1]. Yet, the fact that expert performance relies on a constellation of props scattered in the environment, among which, other experts act as props, gets little attention.

Situated approaches have emerged as new research paradigm in the learning sciences as attempts to understand successful performance in complex domains have supported the idea that cognition is distributed between the knower, the environment, and even the meaning of the activity [19]. Researchers within the situated cognition approach have examined the distributed nature of knowledge work - navy ship navigation [25, p. 47], office systems [28, p. 95], London Underground control rooms, and air traffic control centers [31, p. 14]. Students of the development of scientific knowledge have also found that expert scientist and their trainees reach new understanding about a problem in situated interactions with colleagues; learning is collaboratively generated and depends of the artifacts of available in the domain [17]. The study of how apprentices learn their trade has also supported the idea that cognition is distributed between brains, artifacts and the practices of the domain [17, p. 63]. Learning, according to Lave (1988), is situated as cognition as observed in practice is «distributed - stretched over, not divided among - mind, body, activity and culturally organized settings which include other actors» [2]. In the situated learning view novices undergo a process of cognitive apprenticeship through peripheral participation and under the guidance of an ex- 
pert [5, p. 46]. Learning continues in expert practice through participation in communities of practices [9]. Accordingly, experts scaffold the learning process [35] within activity systems that lead to learning in work spaces such as judicial courts, engineering firms, etc (Engestrom et al. 1999). A situated view of learning recognizes that the individual and the learning environment as inseparable [22, 65] and that the «factoring assumption" according to which individual knowledge can be analyzed apart from any particular context is a theoretical and methodological mistake [19].

In the learning sciences, the recognition of the situated nature of learning and cognition has resulted in an interest in the study of learning environments [8]. The interest is in determining the structural components of the learning environment in a cyclic process of design and redesign guided by the analysis of the learning outcomes that result in each stage. This focus considers the context of learning, yet it cannot per se be considered situated in the sense that it attends to the learner and the environment at different temporal moments of the process - it pays attention to the environment in the design and planning of instruction, to the learner in the execution and evaluation of outcomes, and back to the environment for redesign in a cycle of continuous improvement. Importantly, the expert that guides the process seem to be left out of the picture as the focus goes from the environment to the learner and from the learner back to the environment.

The turtle is slow, or so it seems, because of its very heavy shell. Yet, it is not possible to study its "slowesnness" by only focusing on its heavy shell. The turtle's performance is the result of a very complex constellation of factors. Similarly, domain learning outcomes, in formal and informal environments, in educational and professional ones, are the result of a highly complex constellation of culturally shared and historically generated practices, artifacts, brains and knowledge [16, 51]. Therefore the study of learning in complex domains cannot only be a description and explanation of how brains memorize and represent knowledge, or, as recent research on learning environments suggest, the study of the structural properties of environments that foster learning. Both types of studies are necessary, the representational and the structural, yet the dichotomy between learner and environment is an erroneous application of the insight that cognition is situated and distributed in the environment - a statement that obliges us to consider both, the learner and the environment simultaneously. The challenge to the study of learning in complex domains learning is in how to consider both aspects, the representational one (how representations change) and the structural ones (how the situation, including for instance the teacher's practices and knowledge or the nature of the artifacts involved, fosters learning).

An attempt to understand both the representational and structural aspects of domain learning is the framework proposed by Feldman's «Non-Universal Theory” of cognitive development. In his distinction between what is 'universal' and 'nonuniversal' in human learning Feldman's considers a continuum between what is accessible to all normally endowed human beings by merit of their biology, and what is highly specialized and domain specific in learning and cognitive development. Nonuniversal theory recognizes that there are some aspects of learning that are universal 
and that all learners, through practice and effort, are endowed to achieve. At the opposite end, in what Feldman calls the 'universal to non-universal continuum', are those aspects of learning that also require effort and practice yet are more idiosyncratic and unique: they require some type of formal instruction by an expert in a domain $[14,9]$. Examples of non-universal learning is the learning of scientific concepts as proposed by Vygotsky where there is a need for a zone of proximal development in which an expert recognizes the opportunity to lead the learner to a new level of understanding [35, 101]. In the non-universal end of the continuum experts can introduce changes in the environment with the purpose of scaffolding learning [6]. Feldman's focus has been on the identification of the different cognitive stages in the development of expertise as mapped by an individual learner that is acquiring this expertise, i.e. on the study of expertise development in individual learners. By definition 'nonuniversal' or domain learning requires the presence of the expert and the artifacts of the discipline; yet, in this research programme, nor the role of experts of the disciplinary artifacts are considered. Feldman, despite his attempt to consider the structural aspects of non-universal or domain learning, focuses only in the representational aspects of it - what the learner reports having learned [7, 41]; his focus is on representations of knowledge, not on the structure that supports learning. Again, this is a repetition of the 'either/ or' tendency within the learning sciences, is a repetition of phenomenon by which the structural aspects collapse in favor of the representational ones, or viceversa. As with Simon's case mentioned earlier is another example of the 'factoring assump- tion' $[19,83]$ according to which psychological phenomena must be studied using the individual mind as the unit of analysis. It is as if, even when scientists recognize that there are areas of human performance that require the consideration of the structural aspects of learning in complex domains, the focus ends up being one in which the representational aspects prevail.

To solve the either/or dichotomy between representational and structural approaches I propose a 'complexity assumption': the study of domain learning in terms of what experts do to foster learning, their own, their students, and their domains the management of learning. Assuming that learning management is complex is an invitation to recognize that there are different ways to describe the phenomenon [11;17;18]. The challenge is to offer perspectives that complement each other.

\subsection{The complexity assumption}

There is a general agreement in the learning and cognitive sciences that complex cognitive systems can be described in various ways [7;12;31]. Situated cognition research recognizes three perspectives in its study of expertise as a complex phenomenon: the structural, the behavioral and the functional view $[6,52]$. In cognitive science Newell and Simon have proposed that complex cognitive systems can be described from the temporal perspective [16, 58].

Structural descriptions are descriptions about what parts compose the system and their properties; recent research on learning environments are examples of this perspective. The behavioral description approaches the system in terms of the behaviors of the system and its components; for instance, it attends to the activities by which experts and artifacts interact 
to produce expert performance's results. The functional description approaches the system in terms of the purposes of the system and its components; it is a view presented in terms of goals and intentions. Interestingly, when asked to describe complex systems, novices tend to offer descriptions in terms of structural parts and behaviors; only experts offer descriptions in terms of functions [22]. For instance, when asked to describe a fish tank, biology teachers described it in terms of its structural components - the fish, the stones, the water, etc; the different behaviors of the components - swimming, breathing, eating, etc.; and the functions involved reproduction, survival, interdependence, etc. [26]. Functional descriptions seem to require a certain level of expertise as novices, when asked to describe the same fish tank, described both structural and behavioral properties missing entirely the functional ones [26]. That functional properties seem to be the province of experts, seems also to be reflected by answers to a questionnaire about functional household devices- most subjects declare knowing how they function was, yet only experts go beyond the structural and behavioral properties [25, 36].

Another way of describing a complex cognitive system is in terms of its temporal dimensions [41, 4]. Simon argues that cognitive systems are complex system that can be described in terms of their temporal properties and builds on Allen Newell's analysis of time scales of human action. Newell distinguishes six major time scales for human action the evolutionary, where the time scale is of billions of years, the historic that spans from years to millennia, the social that spans from days to months, the rational and cognitive that span for seconds to hours, and finally, the biological that spans a microseconds to a few milliseconds. The six time scales for human action allow Newell to describe cognition in term of 'temporal bands', in the sense that some of the aspects of the cognitive system can be described as immediate phenomena that impacts sensation and perception, and some aspects are less immediate as their temporal band corresponds to the social and historical bands.

Finally, another way of describing complex cognitive systems is the way that traditionally has been done in cognitive science when describing cognition, learning and expertise: in terms of representational changes. The representational perspective is the perspective in which researchers focus on representational changes in learning and expertise development and performance. It is the most common and until recently the prevalent view in the cognitive sciences.

We have then an acknowledgement that complex cognitive systems can be described in terms of at least these five different perspectives: structural, behavioral, functional, temporal and representational. The complexity assumption states that none of these perspectives have to prevail and exclude the others, instead, they are complementary ways of describing the phenomena of interest.

\section{LEARNING MANAGEMENT THEORY (LMT)}

If learning management is a complex phenomenon, and complex phenomena can be described from different perspectives, then, learning management can be described from at least five different perspectives. If each of these five perspectives offers a theoretical construct or concept, and if the constructs relate to each other in a complementary way, we have then that these constructs constitute a theoretical framework from which to study domain 
learning. The theoretical approach that results from this logical argument is the LMT framework; in what follows I present its constructs identifying the perspective that supports each.

\subsection{LM expertise-driven skill units}

Structurally, complex domain learning is realized in "expertise-skill units». Expertise-driven skill units are systems of goal oriented coordinated activity composed by one or more individuals, domain specific artifacts, and the practices by which they are all engaged in a domain specific task. For example, in the case of software programming, domain learning is realized in a variety of expertise-driven skill units: a reflective professional, a novice-expert dialog, a classroom lesson, a team meeting, etc. In all these cases, one or more individuals participate in goal oriented cognitive processing - problem solving, reasoning, learning, decisionmaking, etc. The purposeful coordination between brains, artifacts, and practices is made possible through the personal development of the individual adaptations of expertise, and the historic and socially shared development of artifacts and practices in a domain. Examples of expertise-driven skill units are the activity systems studied by Engestrom, the distributed cognitive systems described by Hutchins, the learning environments of current learning science research [26], the scientific labs studied by Nersessian [36] and Dunbar [22], the teacher-novice diad of mediated learning of Feurstein [8] and others.

\subsection{LM temporal dimensions}

LM involves various time scales of human action. It involves a shorter time scale when a novice learns something just by hearing it from an expert or reading it in a book. It involves a longer time scale when a student needs to rehearse and elaborate or immerse himself on deliberate practice to achieve certain level of performance [28]. It involves even longer scales of time when experts, after spending 10 or more years immerse in a domain [7, 12]. They need to keep learning and adapting to new situations, practicing to continue improving [28]. A still longer time scale is required to capture the evolution of a discipline where lineages of practices and artifacts are accumulated as repositories to be utilized by current and future members of the discipline. For domains that have been part of human culture since its beginnings, such as mathematics, the time scale is historic. From a LM's perspective, all of these scales are brought to bear in a particular expertise-driven skill unit. For instance, a mathematical operation, multiplication, involves historically developed artifacts, the numbers, and more recent practices, the logarithmic calculation, as well as the direct manipulation of the concepts and procedures by a practicing expert or his/ her apprentices. The concept of temporal dimensions captures the fact that learning management involves both immediate and historic aspects; that some aspects of learning management have taken historic time to develop such as the collection of historically generated practices and artifacts of a domain; that some aspects involve years of practice by individual novices, and that some take days or hours of practice to develop, while some are learned through the immediacy of sensation and perception.

The temporal dimensions are cognitive dimensions as they refer to the time that it takes to humans to adequately attend to a particular situation. In the immediacy of 
sensation and perception the first dimension captures the impact of the artifacts that intervene in a particular expertise-driven skill unit. For instance, artifacts can offer scaffolding (Hmelo-Silver 2006), impact cognitive load [3], be less or more easy or difficult to understand and use (Norman 1993), facilitate or not social presence [31]. In a second band or dimension, learning is not immediate but can take hours, days, or even weeks. This second band has to do with the development of learning beyond mere sensation, perception and memory. It involves understanding, problem solving, communication and other various more permanent or stable demands on cognition. The third band or dimension relates to longer periods of time, in which it is necessary to extend the exposure to a topic to generate learning; it focuses on a concentrated task, or skill that has to be developed as part of domain learning to exhibit expert performance. The evidence suggests that this band can take up to 10 years to develop [28]. Increasing the time scale, superior dimensions have to account for what counts as competent performance in a domain as this can change every few decades, and sometimes take centuries; paradigmatic changes in sciences, for instance, transform what is valued as accomplished or competent performance in a domain. Newtonian and Einsteinian physics are examples of the historic temporal scale.

\subsection{LM design principles}

Functionally, learning management involves engagement with artifacts artifacts have a function, they are engaged with a purpose - they purpose they were intentionally designed to fulfill. Clocks are made to indicate time, cars are made for transportation, and chewing gum is made to chew. The fulfillment of the goal depends on the relationship between the goal, the en- vironment in which the artifact performs, and the properties or characteristics of the artifact [8]. The right combination of goals, environment and properties of the artifact, allow the later to fulfill its function.

To fulfill their purpose, artifacts have functional properties defined by their designers. A hammer has to hammer, a slide rule has to slide and calculate, etc. Hammering is the functional property of a hammer. Calculating is the functional property of a sliding rule. The hammer affords hammering, the slide rule affords calculations, etc. Affordances or functional properties serve as a template of how to design artifacts, how to build them and how to use those [32]. Hammering is a principle od design for a hammer; without it the action of hammering would not be possible. Calculating is a principle of design of a sliding rule, without it, calculations will not be possible. Therefore, we can see how hammering and calculating are design principles, i.e. artifacts have to be designed and engaged with the purpose of reaching these principles. In the case of learning management, there are principles such as problem solving, understanding, collaboration, active learning and other principles that apply.

\subsection{LM best practices}

Behaviorally, experts follow certain practices to foster learning. They engage artifacts in certain ways, through certain behaviors, to achieve certain design principles. These behaviors are learned from previous teachers and previous experiences of learning. Experts use them, purposely, when training novices. These are not random or accidental actions or activities but time-honed practices developed through extensive manipulation of the artifacts of the domain. These practices are designed in the same sense 
that the artifacts used in expert practice are designed. As much as we can think of domain artifacts, a guitar, an aircraft, a software programming language, as designed, the practices by which experts engage them are also designed. Researchers on learning, cognition and education have uncovered numerous best practices that foster learning in a variety of environments, $\mathrm{K}-20$ and professional practice. Attending to individual differences, using various visual and auditory modes of communication, are examples of LM best practices. .

\subsection{LM tools}

LM tools are knowledge representations, concepts, procedures, methods, etc can be internalized by the naked brain and brought to bear to a particular situation [1, 47]. They become tools to achieve a particular goal, a design principle. The representations of knowledge accumulated in a particular discipline are the repositories of data from which the experts manage to deliver solutions to novel problems. LM tools are the various knowledge representations that are brought to the forefront in the expertisedriven skill unit with the purpose of increased learning. A debate, a lecture, a presentation, a team exercise are examples of LM tools.

\subsection{LM theory}

Learning that occurs in expertise-driven skill units can be described in terms of its temporal dimensions: from immediate to historic. The practices by which experts foster learning can be organized according to the design principle they serve, e.g. what is this practice for? Is it a practice that fosters understanding or a practice that foster optimization of memory? Is it a practice that supports active learning? Or, scaffolding? The artifacts used by experts and novices alike have a function. They support particular design principles. Tufts of practices and tools can be organized in this way, in one group the practices that foster understanding, in another group those which foster optimization of memory, or active learning, or social presence, etc. Each tuft defined by the specific design principle it serves: understanding, collaboration, scaffolding, social presence, etc. Each tuft becoming a learning management cluster of principle, practice and tool.

The learning management principles can be classified according to the temporal dimension they attend. Is this a learning management principle that classifies in the immediate or the historic dimension? Understanding, as a principle, seems to relate more to the immediacy dimension while active learning or competent performance seem more related to a less immediate temporal dimension.

In sum, LM can be described in terms of five interrelated constructs: structurally, through LM expertise-driven skill units, temporally, through LM temporal dimensions, functionally, through LM design principles, behaviorally, through LM best practices, and representationally through LM tools. Together they offer a comprehensive view of the learning management construct, what experts do to foster learning in complex domains.

\section{A CASE STUDY}

\subsection{The Higher Education classroom}

In what follows I illustrate LM's concepts using my own experience as the teacher of an undergraduate class in Intellectual Development. The course had 106 undergraduated junior and senior child development majors. 


\section{A.LM expertise-driven skill unit}

The structural description of the expertise-skill unit is similar to the description of a learning environment as currently used in the learning sciences. In this case, the learning environment description involves identifying the participants (two co-teachers (CTs), two teaching assistants (TAs), and 106 students, the organization of the classroom physical space and resources available (chairs, desk, podium, multimedia system, textbook, and other instructional materials), the practices in the classroom and outside of it (journal assignments, classroom assignments and activities, final project, quizzes and the lecture format as a central teaching practice), and other elements that are expertise driven, i.e. expertise-driven because only those things related to our goal - expert performance - are considered in the description. The color of the purses of the teachers is not relevant to the description of the unit.

Over the course of a semester it is possible to define multiple expertise-driven skill units, the classroom as the main unit, but also the TAs conform a sub-unit, as well as the CTs). The group of 106 students as a whole could be seeing as a different unit, different from the classroom which includes the TAs. One particular student is also a unit, as well as a pair teacher-student pair in dialogue. Each unit can be described and analyzed in terms of the remaining concepts of the LM framework. For instance, what is the level of understanding, a design principle, in the overall classroom, or between CTs, or in the unit conformed by CTs and TAs?

\section{B. LM Temporal Dimensions}

The quality of the general result of the program, contrasted with the immediacy of results expected after a semester long course, and the more immediate need of capturing the attention and fostering the understanding of the different topics, becomes a guiding organizing framework for a course such as this: Do we want this course to contribute to a more formal competency as professionals, or do we want only to focus on helping them learn the particular content of the class? Are we paying attention to the longer term expectations the school sets for the students, or only to the immediate result of our lecturing? These considerations align according to different dimensions. For each, there are different practices and principles to follow.

\section{LM Best Practices}

Reading, note-taking, writing, lecturing, meeting with colleagues, preparing quizzes, identifying students' needs, etc. are the practices that in minor or major degree each one of the CTs and TAs engages with. Listening, studying, taking quizzes,

presenting, dialoging, are the different practices the students are involved with. The relationship of these practices to the various design principles and temporal dimensions indicates how well the various principles and dimensions are implemented in this particular case.

\section{LM design principles}

A function that the classroom, as an expertise-driven skill unit has to accomplish is to is to afford 'understanding' of the students. Similarly, there are other functions such as communication, or attention to the unique, etc. These are are standards, i.e. things that we would like to see when observing professional teaching. Us ability is another design principle as the desire is that all elements used in profes- 
sional teaching can be easily understood or captured by the learners.Other design principles, according to research on how people learn, are active learning, authentic learning, competencies, and other design principles in the sense that the goal is to reach these through expert performance, our expert performance as professional teachers.

\section{E. LM Tools for learning}

Expert can bring to bear previous knowledge that can help them adapt to a particular situation to improve performance. Psychological concepts can be used to improve learning (differential intelligence, learning styles, background knowledge, cognitive load, etc.). Assessment techniques can be used formatively to improve learning (one minute essay, summary of the most difficult point, etc.). Specific methods can be used to improve learning (problem-based learning, case study method, debates, etc.). All of these are LM tools.

\section{BIBLIOGRAPHY}

1. Chi, M.T.H., Glaser, R., \& Farr, M.J. (Eds). (1988). The nature of expertise. Hillsdale, NJ: Erlbaum.

2. Chi, M.T.H. (2006). Two approaches to the study of experts' characteristics. In Ericsson, K.A., Charness, N., Feltovich, P.J., \& Hoffman, R.R. (Eds.) The Cambridge handbook of expertise and expert performance. New York, NY: Cambridge University Press.

3. Clancey, W.J. (1997). Situated cognition: On human knowledge and computer representations. Cambridge, UK: Cambridge University.

4. Clark, R.C., Nguyen, F., \& Sweller, J. (2006) Efficienciy in learning. San Francisco, CA: Pfeiffer.

5. Clark, R.C., \& Kwinn, A. (2007) The new virtual classroom, San Francisco, CA: Pfeiffer.

6. Cole, M. (1996). Cultural psychology: A once and future discipline. Cambridge, MA: Belknap of Harvard University.

7. Dunbar, K. (2000). What scientific thinking reveals about the nature of cognition. In Crowley, K., Schunn, C.D., \& Okada, T. (Eds.) Designing for Science: Implications from Everyday, Classroom, and Professional Settings. LEA. Hillsdale: NJ.

8. Engestrom, Y., Miettinen, R., \& Punamaki, R. (eds). (1999). Perspectives on activity theory. New York, NY: Cambridge University Press.

9. Ericsson, K.A., Krampe, R.T., \& Tesch-Romer, C. (1993). The role of deliberate practice in the acquisition of expert performance. Pscyhological Review, 100: 363-406.

10. Ericsson, K.A. (2005). Recent advances in expertise research: A commentary on the contributions to the special issue. Applied Cognitive Psychology, 19: 233-241.

11. Ericsson, K.A. (2006). The influence of experience and deliberate practice on the development of superior expert performance. In Ericsson, K.A., Charness, N., Feltovich, P.J., \& Hoffman, R.R. (Eds.) The Cambridge handbook of expertise and expert performance. New York, NY: Cambridge University Press.

12. Evensen, D., \& Hmelo, C.E. (Eds.) (2000). Problem-based learning: Research perspectives on learning interactions. Mahwah, NJ: Erlbaum.

13. Feldman, D.H. (1979). The mysterious case of extreme giftedness. In Passow, H. (Ed.) The gifted and the talented: 78th yearbook of the NSSE. Chicago, IL: University of Chicago Press.

14. Feldman, D. H., with Goldsmith, L. T. (1986). Nature's gambit: Child prodigies and the development of human potential. New York: Basic Books. 
15. Feldman, D. H. (ed.) (1994) Beyond universals in cognitive development, 2nd edition. Westport, CT: Ablex.

16. Feldman, D.H., Csikszentmihalyi, M., \& Gardner, H. (1994). Changing the world: A framework for the study of creativity. Westport, CT: Greenwood.

17. Feltovich, P.J., Prietula, M.J., \& Ericsson, K.A. (2006). Studies of expertise from psychological perspectives. In Ericsson, K.A., Charness, N., Feltovich, P.J., \& Hoffman, R.R. (Eds.) The Cambridge handbook of expertise and expert performance. New York, NY: Cambridge University Press.

18. Feuerstein, R., Falik, L.H., Feuerstein, R.S., \& RAND, Y. (2004). Creating and enhancing cognitive modifiability: Feuersteins instrumental enrichment program. Jerusalem: The ICELP Press.

19. Greeno, J.G. (1995). Combining analyses of cognitive processes, meanings, and social participation: Understanding symbolic representations. In Moore, J.D., \& Lehman, J.F. (eds.), Proceedings of the Seventeenth Annual Conference of the Cognitive Science Society (pp.591596), Hillsdale, NJ: Erlbaum.

20. Halloran, J., Rogers, Y. and Scaife, M. (2002) Taking the No out of Lotus Notes: Activity Theory, groupware and student groupwork. Proceedings of Computer Supported Collaborative Learning 2002, Denver, January 2002. 169-178.

21. Hmelo-Silver, C.E. (2006). Design principles for scaffolding technology-based inquiry. In O’Donnell, A.M., Hmelo-Silver, C.E., \& Erkens, G. (Eds.) Collaborative learning, reasoning, and technology. Mahwah, NJ: Erlbaum.

22. Hoffman, R.R., \& Woods, D.D. (2000). Studying cognitive systems in context. Human Factors, 42, 1-7.

23. Hughes, J.A., O’Brien, J., Rodden, T., \& Rouncefield, M. (2000). Ethnography, communication and support for design. Luff, P., Heath, C., \& Hindmarsh, J. (eds.) Workplace studies. Cambridge, UK: Cambridge University Press.

24. Hutchins, E. (1995) Cognition in the wild. Cambridge, MA: MIT Press.

25. Keil, F.C. (2006). Explanation and Understanding. Annual Review of Psychology. 57, 227-254.

26. Lave, J. (1988). Cognition in practice: Mind, mathematics, and culture in everyday life. Cambridge, UK: Cambridge University Press.

27. Lave, J., \& Wenger, E. (1991). Situated learning. Cambridge, UK: Cambridge University Press.

28. Mayer, R.E. (2001b). Cognitive constraints on multimedia learning: When presenting more material results in less learning. Journal of Educational Psychology, 93: 187-198.

29. Mayer, R.E. (Ed.) (2005a). The Cambridge handbook of multimedia learning. New York, NY: Cambridge University Press.

30. Nersessian, N.J. (2005). Interpreting scientific and engineering practices: Integrating the cognitive, social, and cultural dimensions. Gorman, M., Tweney, R., Gooding, D., \& Kincannon, A. (eds.) Scientific and technological thinking. Hillsdale, NJ: Erlbaum.

31. Nersessian, N. J. (2006). The cognitive-cultural systems of the research laboratory. Organization Studies, 27(1), 125-145.

32. Nersessian, N. J., Kurz-Milcke, E., Newstetter, W. C., \& Davies, J. (2003). Research laboratories as evolving distributed cognitive systems. Proceedings of The 25th Annual Conference of the Cognitive Science Society. pp. 857-862.

33. Nersessian, N.J., Newstetter, W.C., Kurz-Milcke, E., \& Davies, J. (2003). A mixed-method approach to studying distributed cognition in evolving environments. Proceedings of the International Conference on Learning Sciences, pp. 307-314.

34. Newell, A., \& Simon, H.A. (1972). Human problem solving. Englewood Cliffs, NJ: Prentice-Hall.

35. Newell, A. (1994). Unified theories of cognition. Cambridge, MA: Harvard University Press. 
36. Norman, D.A. (1993). Things that make us smart: Defending human activities in the age of the machine. Reading, MA: Addison-Wesley.

37. Norman, D.A. (1990). The design of everyday things. New York, NY: Doubleday.

38. Resnick, L., Levin, S., \& Teasley, L. (Eds.) (1998). Perspectives of socially shared cognition. Washington, D.C.: American Psychological Association.

39. Rogoff, B. (2003). The cultural nature of human development. New York, NY: Oxford University.

40. Salomon, G. (1993). Distributed cognitions: Psychological and educational considerations. Cambridge, UK: Cambridge University Press.

41. Sawyer, R.K. (1999). The emergence of creativity. Philosophical Psychology, 12, 447-469.

42. Sawyer, R.K. (2006). Analyzing collaborative discourse. In Sawyer, R.K. (Ed.) The Cambridge handbook of the learning sciences. New York, NY: Cambridge University Press.

43. Sternberg, R.J., \& Grigorenko, E.L. (Eds.) (2003). The psychology of abilities, competencies, and expertise. New York, NY: Cambridge University Press.

44. Vygotsky, L. (1978). Mind in society. Cambridge, MA: Harvard University Press. 


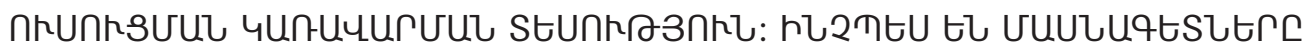

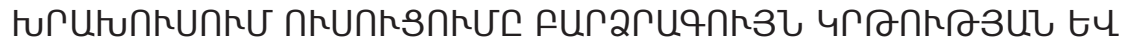

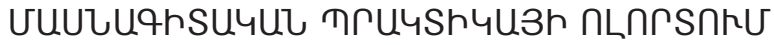

\section{מPhU USUUFGPQGP}

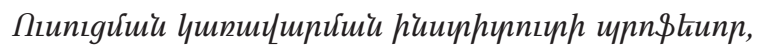
पhükumkn, UUU

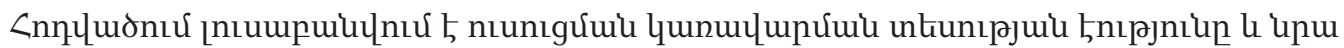

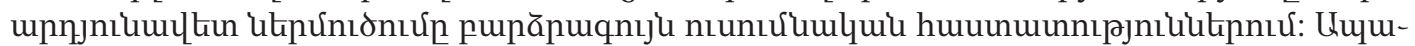

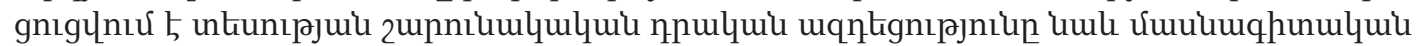

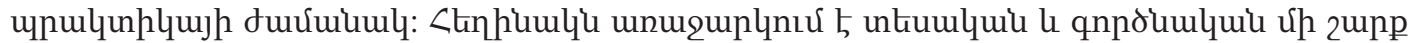

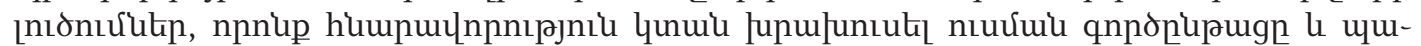

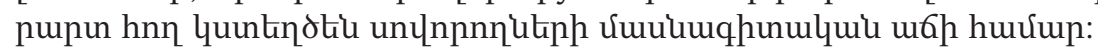

\section{ТЕОРИЯ УПРАВЛЕНИЯ ОБУЧЕНИЕМ. КАК СПЕЦИАЛИСТЫ ПООЩРЯЮТ ОБУЧЕНИЕ В ВУЗЕ В РАМКАХ ПРОФЕССИОНАЛЬНОЙ ПРАКТИКИ}

\section{АЙРИС СТАМБЕРГЕР}

Профессор института управления обучением Винчестер, США

В статье освещается сущность теории управления обучением и ее успешное внедрение в высших учебных заведениях. Доказывается также продолжительное положительное влияние теории в рамках профессиональной практики. Автор предлагает ряд теоретических и практических решений, позволяющих поощрить учебный процесс и создающих плодотворную почву для профессионального роста учащихся. 